\title{
Evaluation of the incidence of gingival recession in the citizens of a large urban agglomeration of the Podlaskie Province in the chosen age groups of 35-44 years and 65-74 years
}

\author{
Ocena występowania recesji dziąseł \\ u mieszkańców dużego miasta województwa podlaskiego \\ w wybranych grupach wiekowych 35-44 oraz 65-74 lat
}

\author{
Magdalena Sulewska, B-D, Jan Pietruski', ${ }^{2}$-F , Renata Górska ${ }^{3, A}$, Edyta Sulima ${ }^{4, B}$, Rafał Świsłocki ${ }^{5, B}$, Agnieszka Paniczko 6, B, \\ Elżbieta Sokal ${ }^{7, B}$, Małgorzata Pietruska ${ }^{3, C, E, F}$ \\ 1 Department of Periodontology and Oral Mucosa Diseases, Medical University of Białystok, Białystok, Poland \\ 2 Private Dental Office, Białystok, Poland \\ 3 Department of Periodontology and Oral Mucosa Diseases, Medical University of Warsaw, Białystok, Poland \\ ${ }^{4}$ Private Dental Practice, Wasilków, Poland \\ 5 Private Dental Practice, Dobrzyniewo Duże, Poland \\ ${ }^{6}$ Agmed Non-Public Healthcare Institute, Białystok, Poland \\ 7 Private Dental Practice, Ełk, Poland \\ A - research concept and design; $\mathrm{B}$ - collection and/or assembly of data; $\mathrm{C}$ - data analysis and interpretation; \\ $\mathrm{D}$ - writing the article; $\mathrm{E}$ - critical revision of the article; $\mathrm{F}$ - final approval of article
}

Address for correspondence

Małgorzata Pietruska

E-mail:mpietruska@wp.pl

Funding sources

none declared

Conflict of interest

none declared

Received on 0ctober 26, 2016

Revised on October 31, 2016

Accepted on November 23, 2016

DOI

$10.17219 / \mathrm{dmp} / 67323$

Copyright

(C) 2017 by Wroclaw Medical University

and Polish Dental Society

This is an article distributed under the terms of the

Creative Commons Attribution Non-Commercial License

(http://creativecommons.org/licenses/by-nc-nd/4.0/)

\section{Abstract}

Background. Gingival recession is a condition affecting all of society. Epidemiological studies on recession incidence in the population are difficult to conduct and interpret due to the complex etiology of this abnormality.

Objectives. The aim of the study was to establish the incidence of gingival recession in adult citizens of a large urban agglomeration of the Podlaskie Province.

Material and methods. The study was carried out on randomly selected citizens of Białystok in 2 age groups. 115 individuals aged 35-44 years and 72 aged 65-74 years were examined. The clinical trial involved an evaluation of the following aspects: recession incidence, extent (depth) and localization. Additionally, Plaque Index (PI) and Bleeding on Probing (BOP) were analyzed.

Results. Gingival recession was observed on at least one surface in about $79.14 \%$ of the individuals analyzed. The most common recession localization was the buccal surface in both the group of 35-44 years $(5.29 \pm 5.23)$ and of $65-74$ years $(6.24 \pm 5.40)$. The lesions were statistically significantly more common on the lower teeth (mandible $7.38 \pm 5.7$ vs maxilla $4.75 \pm 4.67$ ) and lingual surface (lingual surface 3.47 \pm 3.11 vs buccal surface $1.77 \pm 2.39$ ) in the older group. In patients aged $35-44$ years, the mean recession depth was $1.54 \pm 0.55$, while in the case of patients aged $65-74$ years, it was $2.28 \pm 0.9$.

Conclusions. Gingival recession is a common abnormality in the population of adult citizens of large urban agglomerations in the Podlaskie Province.

Key words: epidemiology, gingival recession, adult population

Słowa kluczowe: epidemiologia, recesje dziąsła, populacja osób dorosłych 
Apical displacement of the soft tissue margin in relation to the cemento-enamel junction (CEJ), called gingival recession, is a frequently observed abnormality in persons with various oral cavity hygiene. The individuals who excessively care about hygiene show gingival recession (GR) mainly on the buccal surface of teeth while people with poor oral hygiene and/or untreated periodontitis show recession on every tooth surface. Exposed cement surfaces lead to root caries, non-carious lesions and increased dentine sensitivity. Unfavorable gingival morphology may lead to the accumulation of dental plaque and inhibits preservative and prosthetic treatment. Gingival recession located within the front teeth is the most problematic, especially in the times of aesthetic dentistry. ${ }^{1-4}$

Gingival recession develops for many reasons which include: an abnormal, traumatizing way of brushing teeth, plaque and calculus, anatomical conditions (abnormal setting of a tooth in the arch, thin gingival phenotype, bone dehiscence, high muscle and frenulum attachment) and iatrogenic factors (periodontal procedures, orthodontic treatment, improper preservative and prosthetic treatment). ${ }^{5-14}$ Exposure of the root surface may result from a localized inflammation caused by dental plaque or a generalized form of periodontal inflammation. ${ }^{9,15}$ Zucchelli and Mounssif indicate that GR may be related to a healthy periodontium with lack of bone loss in the interdental spaces or may develop in the course of periodontal inflammation accompanied by the loss of bone of the alveolar process. ${ }^{15}$ In both cases, the etiologic factor related to its development may be the lack of buccal bone of the alveolar process at the site of the recession, which may have an anatomical origin or be acquired (pathological or physiologic). ${ }^{16}$ As regards anatomical causes of a lack of the bundle bone of the alveolar process, Alldritt suggested the following aspects: presence of fenestration and dehiscence of the alveolar process, abnormal setting of a tooth in the arch, individual tooth shape and atypical tooth eruption. ${ }^{17}$ Zucchelli and Mounssif ${ }^{15}$ defined the acquired pathological causes as: improper brushing and flossing, intraoral and perioral piercing, direct trauma related to malocclusion, partial dentures, presence of dental plaque, subgingival cavity margin and prosthetic fillings as well as herpes. The major acquired physiological cause is orthodontic tooth movement beyond the alveolar process which leads to bone dehiscence and constitutes locus minoris resistentiae for the development of gingival recession. ${ }^{15}$ Dominiak and Gedrange report that in today's classification, there are 5 groups of etiological factors leading to development of GR, which are: primary morphological conditions, functional factors, inflammation factors, age and sex, as well as general diseases. ${ }^{18}$

The outcomes of epidemiology research on the incidence of gingival recessions indicate that this condition affects all of society. The frequency of GR fluctuates between 6.3 and $100 \%$ depending on age and increases with age..$^{2,3,4,9,19-21}$ According to a study on a large population of over 30 thousand American people, these changes are present in approximately $23 \%$ of individuals with $10 \%$ frequency in the age group of 30-39 years and over $60 \%$ in the group of 80-90 years. ${ }^{22}$ Due to the complex etiology of gingival recessions, it is very difficult to perform and interpret epidemiology studies evaluating recession incidence in the population. So far, the epidemiological studies performed consider selected etiological aspects or a coincidence of many factors through the creation of multiple regression models and the introduction of independent variables which can influence the occurrence and number of recessions. ${ }^{3,4,6,9,23-28}$ An analysis of these models proves that they are inadequate and the knowledge on recession-causing factors is still insufficient. ${ }^{29}$

The aim of this study was to evaluate the incidence of gingival recession in adult citizens of a large urban agglomeration of the Podlaskie Province.

\section{Material and methods}

The study was carried out in the city of Białystok on randomly chosen citizens aged 35-44 years and 65-74 years. The invitation to the study was sent to 1000 individuals from each age group. 115 persons aged 35-44 including 60 women and 55 men as well as 72 persons aged 65-74 years including 51 women and 21 men reported for the examination. The clinical study was carried out with the use of a periodontal probe (PCPUNC 15, Hu-Friedy Mfg., Chicago, USA) calibrated every $1 \mathrm{~mm}$. The examiners (doctors, dentists) had undergone training in standard calibration.

The study was performed under a program financed by the Ministry of Health, the 'Evaluation of the health condition of the oral cavity and its conditioning in the Polish population aged 35-44 and 65-74 years', approved by the Bioethics Commission of the Medical University of Bialystok (R-I-002/266/2009).

The physical examination comprised the evaluation of gingival recession localization (buccal surface, palatal/lingual surface) and depth, Plaque Index (PI, by O'Leary) and Bleeding on Probing (BOP). PI and BOP were assessed in 4 aspects: buccal, palatal/lingual, mesial and distal). Third molars were not taken into consideration in the study. Recession height was measured from CEJ to gingival margin. In the case of teeth with reconstructions, the gingival edge of the reconstruction was taken as the point of reference. The obtained values were expressed in an approximation to the nearest millimeter. The clinical data was also evaluated depending on the patient's level of education.

The statistical analysis was performed with use of Statistica 12.0 (StatSoft, Tulsa, USA) software. For comparison between groups, the non parametric U Mann-Whitney test was used. The Spearman's rank order correlation coefficient was also determined. The results were considered statistically significant at $\mathrm{p}<0.05$. 


\section{Results}

Gingival recessions were diagnosed in 91 patients aged 35-44 and in 57 patients aged 65-74. In the younger group, recessions were detected in $20.5 \%$ of teeth $(608$ surfaces) while in the older group in $44.8 \%$ (449 surfaces). In the group of younger women, recessions were found in $21.7 \%$ of teeth (335 surfaces), while in men in $19.2 \%$ (273 surfaces). In the group of older women, recessions were observed in $40.3 \%$ of teeth (268 surfaces), while in older men in $47.8 \%$ (181 surfaces).

The analysis of the 2 age groups demonstrated that GR is more common on mandibular teeth $(5.76 \pm 5.24)$, predisposed to the localization on the buccal surface (3.34 \pm $3.22)$. Recession depth was greater in the mandible $(1.82 \pm$ $0.87)$ compared to the maxilla $(1.73 \pm 0.74)$.

Also, apical displacement of the gingival margin was more advanced in lower teeth in both the buccal surface (lower teeth $-18.0 \pm 0.87$ vs upper teeth $-1.76 \pm 0.76$ ) and lingual surface (lower teeth $-1.95 \pm 1.05$ vs upper teeth $-1.82 \pm 1.01)$. The values indicating oral hygiene suggest quite poor hygiene in the studied population. PI was $35.88 \pm 23.22$ while was BOP $36.92 \pm 27.18$. The values of the evaluated variables are presented in Table 1 .

In the group aged 65-74 years, a statistically significantly higher number of tooth surfaces affected by gingival recession $(\mathrm{p}=0.012)$ and mean gingival recession extent $(p=0.000)$ were observed in comparison with the group aged 35-44 years.

The most common gingival recession (GR) localization was the buccal surface in both the group aged 35-44 years $(5.29 \pm 5.23)$ and the group aged $65-74(6.24 \pm 5.40)$. The differences between the groups were insignificant. A significant difference $(\mathrm{p}=0.000)$ was observed in the case of lesions localized on palatal/lingual surfaces, affecting a smaller number of surfaces of the upper teeth $(2.50 \pm$ $3.09)$ compared to the lower teeth $(4.53 \pm 3.61)$. GR on the lingual surface of the lower teeth was significantly more common in the older group $(3.47 \pm 3.11)$ than in the group aged $35-44$ years $(1.77 \pm 2.39)$.

Table 1. Localization and advancement of gingival recession as well as $\mathrm{PI}$ and BOP in the 2 examined age groups of Bialystok citizens (mean \pm standard deviation)

\begin{tabular}{|l|c|c|c|}
\hline Gingival recessions & Maxilla & Mandible & Total \\
\hline Number of tooth surfaces & $3.17 \pm 3.82$ & $5.76 \pm 5.24$ & $8.94 \pm 7.88$ \\
Buccal surface & $2.31 \pm 2.78$ & $3.34 \pm 3.22$ & $5.65 \pm 5.36$ \\
Lingual surface & $0.86 \pm 1.51$ & $2.42 \pm 2.81$ & $3.28 \pm 3.43$ \\
Depth (in mm) & $1.73 \pm 0.74$ & $1.82 \pm 0.87$ & $1.82 \pm 0.79$ \\
Buccal surface & $1.76 \pm 0.76$ & $1.80 \pm 0.87$ & $1.82 \pm 0.82$ \\
Lingual surface & $1.82 \pm 1.01$ & $1.95 \pm 1.05$ & $1.87 \pm 0.93$ \\
PI (\%) & & & $35.88 \pm 23.22$ \\
BOP (\%) & & & $36.92 \pm 27.18$ \\
\hline
\end{tabular}

In the group aged 65-74, a greater advancement of the lesions was observed. Statistically significantly $(\mathrm{p}<0.05)$ higher values of mean gingival recession depth compared to the younger group were observed regardless of the localization of the analyzed pathology in the oral cavity.

Also, significant differences between the groups were found in terms of PI and BOP values. A statistically significantly higher PI $(\mathrm{p}=0.001)$ was found in the group aged 35-44 years, $40.51 \pm 23.59 \%$, compared to the older population where PI was $28.47 \pm 20.7 \%$. Analogically, the BOP value was higher in the group aged 35-44 years $(45.03 \pm 28.45 \%)$ compared to the older group (23.96 \pm 18.95\%). Detailed data is presented in Table 2.

A statistically insignificant increase in the number of gingival recession surfaces in relation to education was found. The lowest number of GR was noted in persons with basic education $(5.55 \pm 6.01)$ while the highest was in persons with higher education $(9.64 \pm 8.1)$. However, the analysis of the number of recessions in the maxilla indicated a statistically significant $(p=0.0294)$ increase in their number in persons with higher education (3.82 $\pm 4.04)$ compared to the individuals with basic education $(1.09 \pm 1.70)$. A statistically significant increase $(\mathrm{p}=$ 0.0474 ) in the number of gingival recessions was also observed in higher education persons in comparison to people with secondary education $(2.64 \pm 3.59)$.

The comparison of gingival recession extent suggested a reverse dependency - the individuals with basic education showed significantly ( $\mathrm{p}=0.0035)$ more extensive gingival recessions $(2.27 \pm 1.60 \mathrm{~mm})$ compared to higher educated persons $(1.65 \pm 0.57)$. The most extensive lesions were observed on mandibular teeth on lingual surfaces in persons with basic education $(2.58 \pm 1.85 \mathrm{~mm})$ while the smallest gingival recessions $(1.33 \pm 0.58 \mathrm{~mm})$, localized on palatal surfaces of upper teeth, were also observed in the individuals with basic education. Detailed data is presented in Table 3.

\section{Discussion}

The studies on gingival recession epidemiology most commonly take into consideration frequency, which is the percentage of persons with gingival recessions in the examined population, scope (range), which corresponds to the number of surfaces (alternatively the number of teeth), severity (intensity, advancement), indicating the scope of exposed root surfaces (vertical extent of recession in $\mathrm{mm}$ ), gingival recession localization in particular teeth and Miller's classification., ${ }^{93-26,30-32}$ Despite frequent observation of gingival recession in adults, epidemiology outcomes suggest great differences depending on the population studied. ${ }^{30}$ According to our own research, gingival recession was observed on at least one surface in about $79.14 \%$ of the individuals and in $20.5 \%$ of teeth in the group of $35-44$ year olds and in $44.8 \%$ of teeth in the 
Table 2. Localization and advancement of gingival recession as well as PI and BOP depending on age (mean \pm standard deviation)

\begin{tabular}{|c|c|c|c|c|c|c|c|c|}
\hline \multirow{2}{*}{\multicolumn{2}{|c|}{ Gingival recession }} & \multirow{2}{*}{\multicolumn{3}{|c|}{$\frac{\text { Adult population }}{\text { age } 35-44}$}} & \multirow{2}{*}{\multicolumn{3}{|c|}{$\frac{\text { Adult population }}{\text { age } 65-74}$}} & \multirow{3}{*}{$\begin{array}{c}p \\
0.971\end{array}$} \\
\hline & & & & & & & & \\
\hline \multirow{9}{*}{$\begin{array}{l}\text { Number of surfaces } \\
\text { with gingival } \\
\text { recession }\end{array}$} & Maxilla buccal surface & 2.30 & \pm & 2.87 & 2.32 & \pm & 2.65 & \\
\hline & Maxilla palatine surface & 0.74 & \pm & 1.43 & 1.06 & \pm & 1.63 & 0.165 \\
\hline & Mandible buccal s. & 2.98 & \pm & 3.10 & 3.92 & \pm & 3.34 & 0.053 \\
\hline & Mandible lingual s. & 1.77 & \pm & 2.39 & 3.47 & \pm & 3.11 & 0.000 \\
\hline & Total buccal surface & 5.29 & \pm & 5.32 & 6.24 & \pm & 5.40 & 0.239 \\
\hline & Total palatine/ling. s. & 2.50 & \pm & 3.09 & 4.53 & \pm & 3.61 & 0.000 \\
\hline & Total maxilla & 3.04 & \pm & 3.75 & 3.38 & \pm & 3.94 & 0.565 \\
\hline & Total mandible & 4.75 & \pm & 4.67 & 7.39 & \pm & 5.70 & 0.001 \\
\hline & Total & 7.79 & \pm & 7.43 & 10.76 & \pm & 8.27 & 0.012 \\
\hline \multirow{9}{*}{$\begin{array}{l}\text { Gingival recession } \\
\text { depth (in } \mathrm{mm} \text { ) }\end{array}$} & Maxilla buccal surface & 1.59 & \pm & 0.63 & 2.00 & \pm & 0.87 & 0.005 \\
\hline & Maxilla palatine surface & 1.53 & \pm & 0.75 & 2.16 & \pm & 1.18 & 0.009 \\
\hline & Mandible buccal s. & 1.49 & \pm & 0.53 & 2.23 & \pm & 1.06 & 0.000 \\
\hline & Mandible lingual s. & 1.56 & \pm & 0.8 & 2.41 & \pm & 1.13 & 0.000 \\
\hline & Total buccal surface & 1.56 & \pm & 0.57 & 2.22 & \pm & 0.99 & 0.000 \\
\hline & Total palatine/ling. s. & 1.53 & \pm & 0.69 & 2.32 & \pm & 1.01 & 0.000 \\
\hline & Total maxilla & 1.55 & \pm & 0.61 & 2.01 & \pm & 0.84 & 0.001 \\
\hline & Total mandible & 1.49 & \pm & 0.57 & 2.31 & \pm & 1.01 & 0.000 \\
\hline & Total & 1.54 & \pm & 0.55 & 2.28 & \pm & 0.90 & 0.000 \\
\hline PI (\%) & $\mathrm{PI}$ & 40.51 & \pm & 23.59 & 28.46 & \pm & 20.70 & 0.001 \\
\hline BOP (\%) & $\mathrm{BOP}$ & 45.03 & \pm & 28.45 & 23.96 & \pm & 18.95 & 0.000 \\
\hline
\end{tabular}

group aged 65-74 years. The outcomes obtained are consistent with the epidemiological study carried out in the USA by Gorman, who detected GR in $78-100 \%$ of middleaged individuals. ${ }^{33}$ The lesions affected $22-53 \%$ of the examined teeth. In Finland, gingival recession was observed in $68 \%$ of the examined individuals present in $11 \%$ of the examined teeth. ${ }^{5}$ In Norway (Oslo), a lower frequency of lesions, $51 \%$, in adults was observed, ${ }^{34}$ while in New Guinea this percentage was even smaller and referred to $11-40 \%$ of adults. ${ }^{35}$

Marini et al. showed a higher frequency of lesions compared to our research. ${ }^{30}$ The authors examined 380 persons over 20 years of age and detected GR on at least one surface of teeth in approximately $89 \%$ of persons. In the group aged 30-39 years, the pathology developed in $96 \%$ of the population while in the group older than 50 years, $98.8 \%$ of the individuals.

According to the comparison of gingival recession presence (\% of persons) in persons aged 30-50 years, ${ }^{2,3,5,10,21,25,30,32}$ the highest frequency was observed in the Brazilian research. Susin et al. showed the presence of lesions in $97.3 \%$ of patients aged $30-49$ years, while Marini et al. showed in $96 \%$ of patients aged $30-39$ years. ${ }^{10,30}$ A high (85\%) frequency of lesions was also shown in Norwegians aged 34-45 years in the study by Löe et al. ${ }^{2}$ In France, Sarfati et al. reported $75.6 \%$ while in Sweden, Serino et al. reported $75 \%$ of gingival recession cases in this age group. ${ }^{32,3}$ The last 2 studies correspond with our results, which showed a similar incidence amounting to $79.13 \%$. According to Khocht et al., gingival recession in the USA develops in 69.6\% of persons aged 30-40 years, which is consistent with the study by Zawada et al., who observed this abnormality in $69.9 \%$ of Wrocław citizens aged 35-44 years. ${ }^{25,29}$ Previous research published in 1989 and 1999 involving similar age groups indicates a lower frequency of lesions - 55.1\% and 56.5\%, respectively. ${ }^{5,21}$ According to cohort research, this phenomenon is caused by a constant increase in both the occurrence and number of gingival recessions. ${ }^{3}$ Therefore, observations conducted at the same time are of the highest comparative value.

According to the observations, the majority of the epidemiological studies indicated that the frequency, scope and severity of gingival recession gradually increase with age. ${ }^{2,5,21,30,33}$ The influence of age on GR frequency increase should probably be explained by the accumulation of numerous recession-contributing factors in time. , $^{61,30,33,36,37}$

According to our research, a higher frequency of gingival recession and greater lesion advancement were observed in the older age group (65-74 years). Statistically significantly higher values of gingival recession depth compared to the younger group were obtained regardless of the localization of the analyzed pathology in the oral cavity. In the case of the younger age group (35-44 years), mean recession depth was $1.54 \pm 0.55 \mathrm{~mm}$, while in patients aged $65-74$ years, it was $2.28 \pm 0.55 \mathrm{~mm}$. These out- 
Table 3. Localization and advancement of gingival recession depending on level of education (mean \pm standard deviation)

\begin{tabular}{|c|c|c|c|c|c|c|c|}
\hline \multirow{2}{*}{ Gingival recession } & & \multicolumn{3}{|c|}{ Education } & \multicolumn{3}{|c|}{$\mathrm{p}$} \\
\hline & & basic - 1 & secondary - 2 & higher - 3 & p1 vs 2 & p1 vs 3 & p2 vs 3 \\
\hline \multirow{9}{*}{$\begin{array}{l}\text { Number of } \\
\text { surfaces with } \\
\text { gingival recession }\end{array}$} & Maxilla buccal surface & $0.73 \pm 1.35$ & $1.68 \pm 2.29$ & $2.97 \pm 3.06$ & 0.1828 & 0.0183 & 0.0026 \\
\hline & Maxilla palatine surface & $0.36 \pm 0.67$ & $0.96 \pm 1.61$ & $0.85 \pm 1.51$ & 0.2304 & 0.2953 & 0.6369 \\
\hline & Mandible buccal s. & $2.55 \pm 3.01$ & $3.29 \pm 3.21$ & $3.46 \pm 3.28$ & 0.4715 & 0.3765 & 0.7243 \\
\hline & Mandible lingual s. & $1.91 \pm 2.77$ & $2.62 \pm 2.93$ & $2.35 \pm 2.74$ & 0.4529 & 0.6110 & 0.5395 \\
\hline & Total buccal surface & $3.27 \pm 3.85$ & $4.97 \pm 4.77$ & $6.43 \pm 5.82$ & 0.2623 & 0.0821 & 0.0775 \\
\hline & Total palatine/ling. s. & $2.27 \pm 3.0$ & $3.58 \pm 3.49$ & $3.20 \pm 3.44$ & 0.2427 & 0.3916 & 0.4764 \\
\hline & Total maxilla & $1.09 \pm 1.70$ & $2.64 \pm 3.59$ & $3.82 \pm 4.04$ & 0.1627 & 0.0294 & 0.0474 \\
\hline & Total mandible & $4.45 \pm 4.59$ & $5.91 \pm 5.65$ & $5.82 \pm 5.02$ & 0.4182 & 0.3907 & 0.9118 \\
\hline & Total & $5.55 \pm 6.01$ & $8.55 \pm 7.79$ & $9.64 \pm 8.10$ & 0.2234 & 0.1075 & 0.3737 \\
\hline \multirow{9}{*}{$\begin{array}{l}\text { Gingival recession } \\
\text { depth (in } \mathrm{mm} \text { ) }\end{array}$} & Maxilla buccal surface & $1.42 \pm 0.38$ & $1.99 \pm 0.85$ & $1.63 \pm 0.67$ & 0.2521 & 0.5869 & 0.0128 \\
\hline & Maxilla palatine surface & $1.33 \pm 0.58$ & $2.09 \pm 1.20$ & $1.60 \pm 0.78$ & 0.2869 & 0.5647 & 0.0469 \\
\hline & Mandible buccal s. & $2.36 \pm 1.76$ & $2.00 \pm 0.99$ & $1.60 \pm 0.59$ & 0.4456 & 0.0160 & 0.0060 \\
\hline & Mandible lingual s. & $2.58 \pm 1.85$ & $2.18 \pm 1.17$ & $1.73 \pm 0.82$ & 0.5255 & 0.0721 & 0.0226 \\
\hline & Total buccal surface & $2.3 \pm 1.72$ & $1.99 \pm 0.92$ & $1.64 \pm 0.59$ & 0.4842 & 0.0346 & 0.0082 \\
\hline & Total palatine/ling. s. & $2.18 \pm 1.58$ & $2.1 \pm 1.02$ & $1.67 \pm 0.74$ & 0.8563 & 0.1518 & 0.0086 \\
\hline & Total maxilla & $1.35 \pm 0.41$ & $1.99 \pm 0.88$ & $1.60 \pm 0.59$ & 0.1618 & 0.4221 & 0.0052 \\
\hline & Total mandible & $2.32 \pm 1.61$ & $1.99 \pm 0.99$ & $1.64 \pm 0.64$ & 0.4777 & 0.0321 & 0.0127 \\
\hline & Total & $2.27 \pm 1.60$ & $2.02 \pm 0.897$ & $1.65 \pm 0.57$ & 0.5431 & 0.0319 & 0.0035 \\
\hline $\mathrm{Pl} \%$ & $\mathrm{PI}$ & $21.02 \pm 16.99$ & $33.87 \pm 22.09$ & $38.60 \pm 23.72$ & 0.0682 & 0.0188 & 0.1798 \\
\hline ВOP\% & BOP & $25.65 \pm 23.89$ & $40.46 \pm 28.69$ & $35.82 \pm 25.98$ & 0.1068 & 0.2174 & 0.2649 \\
\hline
\end{tabular}

comes clearly correspond to French studies. Marini et al. observed mean GR depth of $2.16 \pm 0.79 \mathrm{~mm}$ in the group older than 50 years of age. ${ }^{30}$ The analyzed pathology was detected in over $60 \%$ of the examined teeth.

The most common gingival recession localization in our study was found on the buccal tooth surface in both age groups. According to the analysis of lesion development depending on the localization in the upper or lower dental arch, a more common localization was observed within the lower teeth. Moreover, the number of lower tooth surfaces affected by recession in patients aged 65 74 years old was statistically higher compared to patients aged $35-44$ years $(7.39 \pm 5.7$ vs $4.75 \pm 4.67, \mathrm{p}=0.001)$ Marini et al. also observed the most common (56.33\%) gingival recession localization in mandibular teeth, which was also previously observed by Vehkalahti. ${ }^{30,5}$ A similar (56\%) frequency of GR development was observed by Gorman on upper teeth which, according to the author, is caused by the presence of dehiscence and/or fenestration of buccal bone. ${ }^{33}$ Kozłowski et al. and Zawada et al. also noticed a more frequent GR development on upper teeth. ${ }^{4,29}$

The common development of gingival recession on mandibular teeth is probably related to the characteristics of keratinized gingiva which is wider and probably thicker in the maxilla than in the mandible. ${ }^{38}$ Mendonça observed a high correlation between the depth and quality of gin- giva and gingival recession development. ${ }^{4}$ According to other authors, the areas with gingival deficit in terms of thickness are more susceptible to GR development due to a smaller amount of connective tissue in this site and thus a faster inflammation progression due to the factors that induce and contribute to gingival recession development. ${ }^{36,37,39}$ This data may also explain more frequent GR development on the lingual surfaces of bottom teeth at older age. According to our research, a significantly higher frequency of gingival recession on lingual surfaces in older individuals was observed. Also, a significantly higher presence of this pathology was observed in patients aged $65-74$ years $(4.53 \pm 3.61)$ compared to patients aged $35-44$ years $(2.5 \pm 3.09)$. It ought to be emphasized that the distribution of gingival recession is related to other etiologic factors. The gingival recession present on lower incisors is mostly connected with poor oral hygiene, while on premolars it is with traumatic brushing., ${ }^{9,20}$

Despite the discrepancies related to the main tooth affected by gingival recession, the literature provides unanimous indications that buccal surfaces are the most commonly affected site..$^{21,30,33}$ This correlation was also found in our research. Gingival recession development on buccal surfaces is most of all related to an improper (traumatizing) habit of brushing teeth while on the lingual and approximal surfaces it has mostly to do with poor oral hygiene. $^{2}$ 
Although the distribution pattern may be a vital indication of the major etiologic factors, the cause of the development such changes has not yet been clearly identified. Final diagnosis and interpretation ought to be preceded by correlating a number of variables, which is often difficult and involves the exclusion of potentially predisposing factors. ${ }^{18}$ Due to the multifactorial gingival recession etiology, it is difficult to establish which combination of recession-contributing factors reflects the displacement of the gingival margin below the cemento-enamel junction and the progression (or not) of the vertical extent of gingival recession. Most commonly, an interaction of predisposing (anatomical) and precipitating (acquired) factors occurs leading to gingival recession as a final result. ${ }^{18,29}$

In order to show the relevance of the interaction of the numerous factors on recession development, multiple regression models were constructed and independent variables were introduced. Khocht et al. explained 19\% of gingival recession number changeability on a multiple regression model taking into consideration only age and gender. ${ }^{25}$ The changeability of $31 \%$ was explained by age, brushing frequency, gender and the time of using a hard toothbrush. Also, Checchi et al. used multiple regression in a study on dentistry students and demonstrated that education level in terms of pro-health behaviors may be a crucial factor of developing gingival recession. ${ }^{6}$

Serino et al. reported that $58 \%$ of gingival recession number changeability on buccal surfaces may be explained by a loss of clinical attachment level on interproximal surfaces and the increased severity of inflammation on buccal surfaces as a result of improper hygiene in the entire oral cavity. ${ }^{3}$ Dominiak et al. calculated that $29 \%$ of gingival recession number changeability depends on the influence of 10 variables. ${ }^{27}$ Matas et al. showed that an increase in GR depth within 10 years was $21 \%$ dependent on 4 variables including the presence of dental plaque. ${ }^{26}$ The model of a multiple regression proposed by Wawrzyn-Sobczak explains $41 \%$ of gingival recession number changeability while a study by Kozlowski et al. explained $18 \%$ of this changeability. ${ }^{28,4}$

According to many authors' observations, there is a clear correlation in the relationship between improper or excessive oral hygiene and gingival recession development. ${ }^{3,4,6,25-28}$ Although they are significant factors, they constitute only a part of the etiopathologic factors. The said relationship is presented by our research. A significantly higher PI value was observed in patients aged 35-44 years $(40.51 \pm 23.59 \%)$ compared to older patients who showed a PI value of $28.47 \pm 20.7 \%$. Despite this frequency of developing dental plaque in the younger group of patients, the presence and advancement of lesions displayed lower values compared to the population aged $65-74$ years. The study by Kozłowski et al. demonstrated that a very good oral hygiene in first- and fifth-year students of the Medical Academy in Wroclaw (PI - 21\%) failed to prevent gingival recession development. ${ }^{4}$ The frequency of gingival reces- sion in students, amounting to almost 35\%, ought to be considered high. Excessive hygiene in this group indicated the necessity of reeducation in pro-health behaviors.

In the study by Zawada et al. on Wroclaw citizens aged 35-44 years, no impact of education on gingival recession development was observed. ${ }^{29}$ According to our research, the analysis of GR number in the maxilla showed a statistically significant increase in persons with higher education $(3.82 \pm 4.04)$ compared to the individuals with basic education $(1.09 \pm 1.70)$. A statistically significant increase $(\mathrm{p}=0.0474)$ of GR number was also observed in persons with higher education compared to patients with secondary education $(2.64 \pm 3.59)$. In the comparison of gingival recession extent, a reverse dependency was observed. Persons with basic education showed significantly ( $\mathrm{p}=$ $0.0035)$ more extensive gingival recession $(2.27 \pm 1.60$ $\mathrm{mm}$ ) compared to persons with higher education (1.65 $\pm 0.57 \mathrm{~mm}$ ). The greatest changes were observed on the lingual surfaces of mandibular teeth in persons with basic education $-2.58 \pm 1.85 \mathrm{~mm}$. The smallest $(1.33 \pm 0.58$ $\mathrm{mm}$ ) GR, localized on the palatine surfaces of upper teeth, was also observed in persons with basic education.

\section{Conclusions}

Gingival recession is a common abnormality in the population of adult citizens of large urban agglomerations in the Podlaskie Province. Due to the complex etiology of gingival recession, epidemiology studies evaluating recession incidence in the population are difficult to carry out and interpret.

\section{References}

1. Löe $H$, Anerud A, Boysen $H$, Smith M. The natural history of periodontal disease in man: The rate of periodontal destruction before 40 years of age. J Periodontol. 1978;49:607-620.

2. Löe $H$, Anerud A, Boysen $H$. The natural history of periodontal disease in man: Prevalence, severity, and extent of gingival recession. J Periodontol. 1992;63:489-495.

3. Serino G, Wennström JL, Lindhe J, Eneroth L. The prevalence and distribution of gingival recession in subjects with a high standard of oral hygiene. J Clin Periodontol. 1994;21:57-63.

4. Kozłowski Z, Konopka T, Karolewska E, Mendak M, Szulc M. Occurrence of gingival recessions in students from the first and the last year of dentistry. Dent Med Probl. 2003;40:391-397 [in Polish].

5. Vehkalahti M. Occurrence of gingival recession in adults. J Periodontol. 1989;60:599-603.

6. Checchi L, Daprile G, Gatto MRA, Pelliccioni GA. Gingival recession and toothbrushing in an Italian School of Dentistry: A pilot study. J Clin Periodontol. 1999;26:276-280.

7. Löst C. Depth of alveolar bone dehiscences in relation to gingival recessions. J Clin Periodontol. 1984;11:583-589.

8. Kassab MM, Cohen RE. The etiology and prevalence of gingival recession. J Am Dent Assoc. 2003;134:220-225.

9. Van Palenstein Helderman WH, Lembariti BS, Van Der Weijden GA, Van't Hof MA. Gingival recession and its association with calculus in subjects deprived of prophylactic dental care. J Clin Periodontol. 1998;25:106-111.

10. Susin C, Haas AN, Oppermann RV, Haugejorden O, Albandar JM. Gingival recession: Epidemiology and risk indicators in a representative urban Brazilian population. J Periodontol 2004;75:1377-1386. 
11. Lindhe J, Nyman S. Alterations of the position of the marginal soft tissue following periodontal surgery. J Clin Periodontol. 1980;7:525530.

12. Lang NP. Periodontal considerations in prosthetic dentistry. Periodontol 2000. 1995;9:118-131.

13. Matthews DC, Tabesh M. Detection of localized tooth-related fac tors that predispose to periodontal infections. Periodontol 2000. 2004:34:136-150.

14. Smith RG. Gingival recession. Reappraisal of an enigmatic condition and a new index for monitoring. J Clin Periodontol. 1997;24:201-205.

15. Zucchelli G, Mounsif I. Periodontal plastic surgery. Periodontol 2000. 2015;68:333-368

16. Geiger A. Mucogingival problems and the movement of mandibular incisors: A clinical review. Am J Orthod. 1980;78:511-527.

17. Alldritt W. Abnormal gingival form. Proc R Soc Med. 1968;61:137-142.

18. Dominiak M, Gedrange T. New perspectives in the diagnostic of gingival recession. Adv Clin Exp Med 2014;23:857-863.

19. Källestal C, Uhlin S. Buccal attachment loss in Swedish adolescents. J Clin Periodontol. 1992;19:485-491.

20. Joshipura K, Kent R, Depaola P. Gingival recession: Intra-oral distribution and associated factors. J Periodontol. 1994;65:864-871.

21. Albandar JM, Kingman A. Gingival recession, gingival bleeding and dental calculus in adults 30 years of age and older in the United States, 1988-1994 - National Institute of Dental and Craniofacial Research, National Institutes of Health. J Periodontol 1999;70:30-43.

22. Albander JM. Periodontal diseases in North America. Periodontology 2000. 2002;29:31-69.

23. Muller HP, Stadermann S, Heinecke A. Gingival recession in smok ers and non-smokers with minimal periodontal disease. J Clin Periodontol. 2002;29:129-136.

24. Miller PD. A classification of marginal tissue recession. Int J Periodont. 1985:5:9-13.

25. Khocht A, Simon G, Person P, Denepitiya JL. Gingival recession in relation to history of hard toothbrush use. J Periodontol. 1993; 64:900-905.

26. Matas F, Sentis J, Mendieta C. Ten-year longitudinal study of gingival recession in dentists. J Clin Periodontol. 2011;38:1091-1098.
27. Dominiak M, Konopka T, Szajowski K. Gingival recession with regard to the potential etiopatological factors. Stomatol Wspot. 2002;9:22-28 [in Polish].

28. Wawrzyn-Sobczak K. Gingival recession - etiology, incidence and treatment. Doctoral thesis, Białystok 2003 [in Polish].

29. Zawada $\measuredangle$, Konopka T, Chrzęszczyk D. Prevalence of the gingival recessions in adult residents of Wrocław. Dent Med Probl. 2012;49:383-390 [in Polish]

30. Marini MG, Greghi SLA, Passanezi E, Sant'Ana ACP. Gingival recession: Prevalence, extension and severity in adults. J Appl Oral Sci. 2004;12:250-255.

31. Geiser EJ, Kleisner J, Marinello CP. Gingivale Rezession. Eine Übersicht über Prävalenz, Ätiologie und Klassifikation. Schweiz Monatsschr Zahnmed. 1993;103:1278-1287.

32. Sarfati A, Bourgeois D, Katsahian S, Mora F, Bouchard P. Risk assessment for buccal gingival recession defects in an adult population. J Periodontol. 2010;81:1419-1425.

33. Gorman WJ. Prevalence and etiology of gingival recession. J Periodontol. 1967:38:316-322.

34. Sangnes G, Gjermo P. Prevalence of oral soft and hard tissue lesions related to mechanical toothcleansing procedures. Community Dent Oral Epidemiol. 1976;4:77-83.

35. Schamschula RG, Keyes PH, Hornabrook RW. Root surface caries in Lufa, New Guinea. I. Clinical observations. J Am Dent Assoc. 1972;85:603-608.

36. Baker DL, Seymour GJ. The possible pathogenesis of gingival recession. A histological study of induced recession in the rat. J Clin Periodontol. 1976;3:208-219.

37. Ericsson I, Lindhe J. Recession in sites with inadequate width of the keratinized gingiva. An experimental study in the dog. J Clin Periodontol. 1984;11:95-103.

38. Bednarz W, Zielińska A. Ultrasonic biometer and its usage in an assessment of periodontal soft tissue thickness and comparison of its measurement accuracy with a bone sounding method. Dent Med Probl. 2011;48:481-489.

39. Kennedy JE, Bird WC, Palcanis KG, Dorfman HS. A longitudinal evaluation of varying widths of attached gingiva. J Clin Periodontol. 1985;12:667-675. 